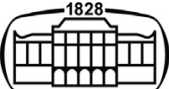

AKADÉMIAI KIADÓ Addictions

10 (2021) 1, 181-193

DOl:

$10.1556 / 2006.2020 .00103$

(c) 2020 The Author(s)

\title{
A test of the pathway model of problematic smartphone use
}

Journal of Behavioral

\section{NATALE CANALE $^{1 *} \odot$, TANIA MORETTA ${ }^{2} \odot$, LUCA PANCANI $^{3} \odot$, GIULIA BUODO ${ }^{2} \odot$, ALESSIO VIENO $^{1} \odot$, MARIO DALMASO $^{1}{ }^{\circledR}$ and JOËL BILLIEUX ${ }^{4} \odot$}

\author{
${ }^{1}$ Department of Developmental and Social Psychology, University of Padova, Padova, Italy \\ ${ }^{2}$ Department of General Psychology, University of Padova, Padova, Italy \\ ${ }^{3}$ Department of Psychology, University of Milano-Bicocca, Milan, Italy \\ ${ }^{4}$ Institute of Psychology, University of Lausanne, Lausanne, Switzerland
}

Received: September 18, 2020 • Revised manuscript received: December 05, 2020 • Accepted: December 06, 2020 Published online: January 20, 2021

\section{FULL-LENGTH REPORT}

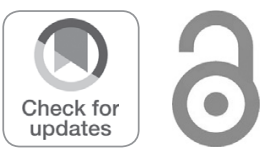

* Corresponding author.

E-mail: natale.canale@unipd.it

\begin{abstract}
Background and aims: Problematic smartphone use (PSU) has been described as a growing public health issue. In the current study, we aimed to provide a unique and comprehensive test of the pathway model of PSU. This model posits three distinct developmental pathways leading to PSU: (1) the excessive reassurance pathway, (2) the impulsive pathway and (3) the extraversion pathway. Methods: Undergraduate students $(n=795,69.8 \%$ female, mean age $=23.80$ years, sd $=3.02)$ completed online self-report measures of PSU (addictive use, antisocial use and dangerous use) and the psychological features (personality traits and psychopathological symptoms) underlying the three pathways. Results: Bayesian analyses revealed that addictive use is mainly driven by the excessive reassurance pathway and the impulsive pathway, for which candidate etiopathological factors include heightened negative urgency, a hyperactive behavioural inhibition system and symptoms of social anxiety. Dangerous and antisocial use are mainly driven by the impulsive pathway and the extraversion pathway, for which candidate etiopathological factors include specific impulsivity components (lack of premeditation and sensation seeking) and primary psychopathy (inclination to lie, lack of remorse, callousness and manipulativeness). Discussion and conclusions: The present study constitutes the first comprehensive test of the pathway model of PSU. We provide robust and original results regarding the psychological dimensions associated with each of the postulated pathways of PSU, which should be taken into account when considering regulation of smartphone use or tailoring prevention protocols to reduce problematic usage patterns.
\end{abstract}

\section{KEYWORDS}

problematic smartphone use, pathway model, undergraduate students, personality traits, psychopathological symptoms, Bayesian analytical approach

\section{INTRODUCTION}

In the last two decades, a growing number of studies have found that excessive smartphone use is related to a wide range of negative consequences, such as addiction-like symptoms (e.g. loss of control, apparent withdrawal and tolerance, and interference with daily life), emotional symptoms (e.g. depression and anxiety), road accidents and interference with sleep (Billieux, 2012; De-Sola Gutiérrez, Rodríguez de Fonseca, \& Rubio, 2016; Elhai, Dvorak, Levine, \& Hall, 2017). From a developmental perspective, the ongoing digital technology revolution naturally increases and expands the ordinary adolescent proclivities to explore, seek and learn from socially and affectively salient experiences (Giovanelli, Ozer, \& Dahl, 2020). Previous research suggests that children, adolescents and young adults (often described as 'digital natives') might be a particularly vulnerable population, as they frequently 
display heavy mobile phone usage patterns (Cheever, Rosen, Carrier, \& Chavez, 2014; Giovanelli, Ozer, \& Dahl, 2020; Lepp, Barkley, \& Karpinski, 2014; Lepp, Li, Barkley, \& Salehi-Esfahani, 2015; Smetaniuk, 2014; Walsh et al., 2020).

In view of these issues, it is of paramount importance to focus research on the public health implications and risk associated with excessive problematic mobile phone use. Problematic smartphone use (PSU) has been defined as an uncontrolled pattern of smartphone use linked with impairment in academic, occupational and/or social functioning (Billieux, Maurage, Lopez-Fernandez, Kuss, \& Griffiths, 2015). Although PSU presents overlapping symptoms with addictive behaviours (e.g., loss of control, tolerance-like and withdrawal-like phenomena) (see De-Sola Gutiérrez et al., 2016 for a review), its recognition as a potential addictive disorder is debated (Billieux et al., 2017; Montag, Wegmann, Sariyska, Demetrovics, \& Brand, 2020; Panova \& Carbonell, 2018).

Despite the blossoming of PSU research, uncertainty still abounds regarding the psychological factors that may be implicated in PSU, as most research in this field has been conducted in the absence of theoretical models. Although PSU has been generally viewed either as a genuine addictive disorder (a behavioural addiction) (Choliz, 2010; Montag et al., 2020) or as 'compensatory' behaviour displayed by individuals who present emotional symptoms (e.g. anxiety, depression, stress) and maladaptive emotion regulation strategies (Elhai, Yang, \& Montag, 2019a; Elhai, Levine, \& Hall, 2019b), few theoretical models of PSU have been formulated. One notable exception is the framework proposed by Billieux and colleagues (Billieux, 2012; Billieux et al., 2015) to account for the multiple forms and etiologies of PSU. This model proposed three distinct developmental pathways to PSU, each being associated with distinct psychosocial and psychopathological variables: (1) the excessive reassurance pathway, (2) the impulsive pathway and (3) the extraversion pathway. The excessive reassurance pathway comprises individuals whose PSU is mainly driven by the necessity to maintain relationships and obtain reassurance from others (Ha, Chin, Park, Ryu, \& Yu, 2008; Lu, Katoh, Chen, Nagata, \& Kitamura, 2014). This pathway is postulated to typically result in perceived dependence on the mobile phone and/or addiction-like symptoms (e.g., tolerance). Such a pathway was formulated on the basis of numerous studies that linked PSU to childhood maltreatment and a poor self-model of adult attachment, low selfesteem, and heightened levels of general and social anxiety, depression or neuroticism (Emirtekin, 2019; Igarashi, Motoyoshi, Takai, \& Yoshida, 2008; Lu et al., 2014; Lepp et al., 2015). This excessive reassurance pathway is consistent with the hypothesis proposed by Elhai and colleagues (2019a, b) that PSU is mainly driven by negative reinforcement (e.g. a way for anxious or depressed people to cope with negative emotions and distract themselves from these emotions) and can be viewed as a maladaptive coping strategy. The impulsive pathway corresponds to PSU patterns promoted by poor impulse control, ultimately resulting in uncontrolled urges and dysregulated use. The existence of this pathway is supported by research that linked PSU with specific impulsivity traits, such as lack of planning/premeditation and urgency (the tendency to act rashly in intense emotional contexts) (Billieux, Van der Linden, \& Rochat, 2008; Fjeldsoe, Marshall, \& Miller, 2009; Khang, Kim, \& Kim, 2013). It was also suggested that this pathway characterises individuals with aggressive and antisocial personality traits. Notably, this impulsive pathway might lead to various forms of PSU, including addictive use, antisocial use (e.g. using the mobile phone in banned places or in an aggressive way) or dangerous use (e.g. using the mobile phone while driving and in other hazardous situations) (Billieux, 2012; Billieux et al., 2008). Finally, the extraversion pathway is defined as the consequence of reward and excitement-driven smartphone usage patterns potentially linked to a wide range of risky behaviours (e.g. phoning while driving, sexting). The existence of this pattern is supported by studies that showed that PSU is linked with high extraversion and increased levels of sensation seeking (Augner \& Hacker, 2012; Ehrenberg, Juckes, White, \& Walsh, 2008), need for stimulation and excitement, and a high sensitivity to rewards (Igarashi et al., 2008). A fundamental aspect of this model is that it assumes not only that various pathways can lead to different manifestations of PSU (addictive, dangerous and antisocial use), but also that various pathways can lead to similar manifestations or 'symptoms' through the interplay of different etiological mechanisms. In particular, within this model, addictive use of the mobile phone can be viewed as the result of either emotional and attachment-related variables (excessive reassurance pathway) or impulsivity and self-control-related variables (impulsive pathway), which might resolve the recurrent debate that opposes the addictive behaviour (Choliz, 2010; Montag et al., 2020) versus maladaptive coping hypotheses of PSU (Elhai et al., 2019a,b).

Although the pathway model developed by Billieux and colleagues (2015) is frequently used to theoretically anchor PSU research and/or interpret related research findings, this model has received little direct empirical support to date. In a recent study conducted in a representative sample of Swiss men, Dey et al. (2019) tested how psychological factors underlying the three postulated pathways predicted addictive use of smartphones. These authors found that psychological factors underlying the excessive reassurance pathway (depression, social anxiety) and the impulsive pathway (attention deficit hyperactivity disorder, aggression-hostility), but not the extraversion pathway, predicted addictive smartphone use. In another study, Pivetta et al. (2019) provided partial support for the pathway model of PSU through a path analysis in which psychological factors included in the pathway model were used to predict different types of PSU. The results showed that trait neuroticism specifically predicted addictive smartphone use, whereas impulsivity traits (assessed by the Barratt Impulsivity Scale; Patton, Stanford, \& Barratt, 1995) predicted all types of PSU, namely addictive, dangerous and antisocial use. Contrary to what was formulated in the model, extraversion was not found to predict PSU. The major limitation of these 
preliminary attempts to validate the pathway model of PSU is the absence of some key model variables, including emotion-related impulsivity traits (which have been systematically linked to PSU and which are not measured by the Barratt Impulsivity Scale) or psychopathy-related personality traits.

To address this gap in the literature, we aimed in the present study to provide the first comprehensive test of the pathway model of PSU in young adults (e.g. undergraduate students) by considering the specific personality traits that were not included in the preliminary validation attempts of the model (Dey et al., 2019; Pivetta, Harkin, Billieux, Kanjo, \& Kuss, 2019). Notably, Billieux et al. (2015) stated that the three PSU pathways should not be considered as mutually exclusive, and it is possible that interactions among different factors may occur in some cases of PSU (e.g. a smartphone user characterised simultaneously by poor self-esteem and high impulsivity). In order to directly take into account this model premise, in the present study we used a Bayesian approach that allowed us to (statistically) consider the three pathways as being not mutually exclusive.

Capitalising on a Bayesian approach, we were able to test all possible combinations among personality traits and psychopathological features characterising the assessed developmental pathways leading to PSU (i.e. addictive, dangerous and antisocial use). In other words, starting from the 'prior assumption' that all the personality traits and psychopathological features have the same probability of being included in the three pathways that are postulated in the model, we tested whether their posterior probabilities in describing addictive, antisocial and dangerous patterns of smartphone use matched the relationships hypothesised by the pathway model of PSU. In line with the initial formulations of the pathway model of PSU (Billieux et al., 2015), we predicted that (1) psychological factors associated with the three pathways (e.g. impulsivity traits, emotional symptoms) would be associated with addictive use of the smartphone and (2) psychological factors underlying the impulsive pathway (e.g. impulsivity trait, psychopathic trait, aggressiveness) and the extraversion pathway (e.g. sensation seeking, extraversion, sensitivity to reward) would be associated with dangerous and antisocial smartphone use.

\section{METHODS}

In this study, we used data from a cross-sectional online survey available from June 13 to October 15, 2019. Participants were recruited through online advertisements shared in local online messaging boards and social network groups. Interested participants were directed to an online informed consent statement. Inclusion criteria included (1) being a college student (2) being young adults aged 18-35 years and (3) being fluent in Italian. Participants had the opportunity to receive compensation (25 Euros) by taking part in a lottery of 10 prizes. Anonymity of the participants was guaranteed (no personal data or Internet Protocol addresses were collected) unless participants wanted to take part in the lottery by providing their e-mail address and personal details (name and surname) at the end of the survey (these data were dissociated from the data set before the analyses to ensure anonymity). The entire online survey (173 items) took approximately $30 \mathrm{~min}$ to complete. In total, 1,397 participants started the survey, of whom 187 were excluded because they did not meet the inclusion criteria. Another 413 potential participants were removed because either (1) they did not respond correctly on a set of four items that aimed to identify careless answering (e.g. 'click now on number 3') or (2) they did not complete all of the items in the survey. Participants who reported non-binary gender self-identification were also excluded because of the small number in our sample $(n=2)$. The final sample comprised 795 participants whose demographic characteristics are presented in Table 2. This study was part of a larger research project on smartphone use in Italian college students; other data not related to this study will be presented elsewhere.

\section{Measures}

After completing a series of questions on demographics (i.e. gender, age, employment, relationship status and place of residence), participants were invited to fill in a series of validated questionnaires.

Questionnaires included in the online survey were selected to prioritise instruments that have been validated and for which published versions exist in Italian. PSU was assessed by using the short version of the Problematic Mobile Phone Use Questionnaire (Lopez-Fernandez et al., 2018), which measures different types of PSU, namely addictive use (e.g. difficulty controlling smartphone use), antisocial use (e.g. using the mobile phone in banned places) and dangerous use (e.g. using the mobile phone while driving).

Other questionnaires were selected to assess the psychological factors (personality traits and psychopathological symptoms) underlying the three pathways (i.e. reassurance seeking, impulsive, extraversion) postulated by Billieux et al. (2015). Impulsivity traits (i.e. lack of premeditation, lack of perseverance, negative urgency, positive urgency and sensation seeking) were assessed by using the Italian version of the Short UPPS-P Impulsive Behaviour Scale (D'Orta et al., 2015). Aggressive traits were measured with the Italian validation of the Aggression Questionnaire (Fossati, Maffei, Acquarini, \& Di Ceglie, 2003). Extraversion and neuroticism were measured by selecting specific subscales of the Big Five Questionnaire - Short Version (Italian version: Caprara, Barbaranelli, Borgogna, \& Perugini, 1993). Psychopathic traits were measured with the Italian version of the Levenson Self-Report Psychopathy Scale (Somma, Fossati, Patrick, Maffei, \& Borroni, 2014). The Behavioural Activation System (i.e., reward responsiveness, reward drive and fun seeking) and the Behavioural Inhibition System were assessed by using the Italian version of the BIS/BAS scales (Leone, Pierro, \& Mannetti, 2002). A series of additional questionnaires were used to measure psychopathological 
symptoms. Social anxiety was measured with the Italian version of the Social Interaction Anxiety Scale (Sica et al., 2007). Emotional symptoms (stress, anxiety and depression) were measured with the short-form version of the Depression Anxiety Stress Scales (Italian version: Bottesi et al., 2015). Finally, self-esteem was measured by using the Italian version of the Rosenberg Self-Esteem Scale (Prezza, Trombaccia, \& Armento, 1997). Table 1 comprehensively describes all the questionnaires and variables included in the present study.

\section{Analysis}

Analyses were performed with $\mathrm{R}$ software ( $\mathrm{R}$ Core Team, 2018). The existence of three developmental pathways leading to PSU was tested by assessing the possible contributions of personality measures and psychopathological symptoms (i.e. statistical predictors) to addictive, antisocial and dangerous mobile phone use (i.e. dependent variables) through a Bayesian approach, which is considered a powerful procedure for testing hypotheses in psychological research (Wagenmakers et al., 2018; West, 2016). More specifically, Bayesian inference permits quantification and assessment of evidence in favour of both the null hypothesis and of alternative hypotheses (Wagenmakers et al., 2018), and the Bayesian parameter estimation is not affected by the sampling plan (Schönbrodt, Wagenmakers, Zehetleitner, \& Perugini, 2017). Here, Bayesian adaptive sampling for variable selection and model averaging (R package: BAS; the $\mathrm{R}$ script is available at https://github.com/TaniaMoretta/Atest-of-the-pathway-model-of-problematic-smartphone-useBayesian-model-averaging; Clyde, Ghosh, \& Littman, 2011) was used to assess what combination of statistical predictors provided an adequate description of the distributions that generated the observed addictive, antisocial and dangerous patterns of mobile phone use. Specifically, 19,792 models (all possible combinations between predictors when taking gender into account) were estimated by a Markov Chain Monte Carlo sampling method by using the Zellner-Siow Cauchy prior on the coefficients (i.e. all Bayes factors are compared with the null model) and a uniform prior distribution over the models (i.e. by assigning equal probabilities to all models). The null hypothesis was rejected when the 95\% Bayesian credibility intervals (BCIs) did not include the null value (Kruschke, 2014). As an extension of Bayesian inference, this approach considers parameter uncertainty through prior distribution and model uncertainty and obtains posterior distributions for the model parameters and the model by using Bayes' theorem, allowing for model selection and combined estimation (Clyde, 2011; Fragoso, Bertoli, \& Louzada, 2018).

Multicollinearity was monitored by examining the variance inflation factor (VIF). In this study, the VIF indicated that multicollinearity was not a concern (see Supplement, section 1).

Residual plots were used to evaluate the normality and homogeneity of variance. The scatterplot of the standardised residuals showed that the data met the assumptions of homogeneity of variance and linearity (see Supplement, section 2).

\section{Ethics}

Ethical clearance was obtained from the ethical committee of the University of Padova (protocol number: 3,104). This study did not involve human and/or animal experimentation.

\section{RESULTS}

Descriptive statistics and correlations between variables are reported in Table 2. In the present study, skewness and kurtosis values were all less than 0.80 and 0.56 , respectively, indicating that the distributions of variables closely mirrored a normal distribution.

The associations between potential predictors and addictive, antisocial and dangerous patterns of smartphone use were modelled through a Bayesian approach. Considering the addictive pattern of smartphone use as the dependent variable, social anxiety, behavioural inhibition, negative urgency, primary psychopathy and BAS-RR showed marginal posterior inclusion probabilities (PIPs) of $>0.5$. However, across the 19,792 models, the combination of social anxiety, behavioural inhibition, negative urgency and primary psychopathy was the more plausible in describing the addictive pattern of use; i.e. it received the highest posterior probability (Bayes factor $(\mathrm{BF})=1 ; R^{2}=0.13$ ). Therefore, we focused on these predictors in subsequent analyses. The $95 \%$ BCIs showed that higher levels of an addictive pattern of mobile use were associated with higher negative urgency $(\beta=0.22,95 \% \mathrm{BCI}=[0.14 ; 0.30])$, higher behavioural inhibition $(\beta=0.11,95 \% \mathrm{BCI}=[0.06 ; 0.16])$, higher primary psychopathy $(\beta=0.06,95 \% \mathrm{BCI}=[0.03$; $0.10])$ and higher social anxiety $(\beta=0.02,95 \% \mathrm{BCI}=[0.01$; $0.04])$.

Considering the antisocial pattern of smartphone use as the dependent variable, lack of premeditation, sensation seeking, aggressive traits and primary psychopathy showed marginal PIPs of $>0.5$, and their combination was the more plausible in describing the antisocial pattern of use $(\mathrm{BF}=1$; $R^{2}=0.14$ ). The $95 \%$ BCIs showed that higher levels of an antisocial pattern of smartphone use were associated with higher lack of premeditation $(\beta=0.17,95 \% \mathrm{BCI}=[0.09$; $0.24])$, higher sensation seeking $(\beta=0.08,95 \% \mathrm{BCI}=[0.02$; $0.13])$, higher levels of aggressive traits $(\beta=0.02,95 \% \mathrm{BCI}$ $=[0.01 ; 0.03])$ and higher primary psychopathy $(\beta=0.07$, 95\% BCI $=[0.04 ; 0.10])$.

Finally, considering the dangerous pattern of smartphone use as the dependent variable, lack of premeditation, sensation seeking and primary psychopathy showed marginal PIPs of $>0.5$, and their combination was the more plausible in describing the antisocial pattern of use $(\mathrm{BF}=1$; $R^{2}=0.16$ ). The $95 \%$ BCIs showed that higher levels of an antisocial pattern of mobile use were associated with higher lack of premeditation $(\beta=0.30,95 \% \mathrm{BCI}=[0.22 ; 0.39])$, 
Table 1. Characteristics and reliability for the scales

\begin{tabular}{cc}
\hline Tools & $\begin{array}{c}\text { Authors (Italian } \\
\text { version) }\end{array}$ \\
\hline $\begin{array}{c}\text { DASS }- \\
21\end{array}$ & $\begin{array}{c}\text { Henry \& Crawford, } \\
\text { 2005 (Bottesi et al., } \\
\text { 2015) }\end{array}$ \\
& \\
& \\
& \\
SIAS & Mattick \& Clarke, 1998 \\
& (Sica et al., 2007) \\
& \\
BIS/BAS & Carver \& White 1994 \\
scale & (Leone, Pierro \& \\
& Mannetti, 2002)
\end{tabular}

$\begin{array}{cl}\text { BFQ - } & \text { Caprara, Barbaranelli, } \\ \text { SV } & \text { Borgogna \& Perugini, }\end{array}$ (1993)

RSES Rosenberg, 1965

(Prezza, Trombaccia \& Armento, 1997)

S-UPPS- Billieux et al., 2012

P (D'Orta et al., 2015)

\begin{tabular}{ccccc} 
Definition & Items & Likert response format & $\begin{array}{c}\text { Reliability values } \\
\text { (Cronbach's alpha) }\end{array}$ & $\begin{array}{c}\text { Postulated } \\
\text { pathway }\end{array}$ \\
\hline Emotional distress in & 21 & $\begin{array}{c}\text { 4-point ranging from } \\
\text { (never or almost } \\
\text { hree subcategories of }\end{array}$ & Total score: 0.93 & $\begin{array}{c}\text { Reassurance } \\
\text { seeking }\end{array}$ \\
never) to 3 (almost & &
\end{tabular}

self-esteem/incentives and depressed mood), anxiety (e.g. fear and anticipation of negative events) and stress (e.g. persistent state of over arousal and low frustration tolerance) Anxiety over social interactions (e.g. 'I have difficulty talking with other people')

Behavioural inhibition system (BIS): sensitivity to aversive stimuli (e.g. worrying about making mistakes)

Behavioural activation system scales (BASs) Reward Responsiveness

(RRs): sensitivity to anticipated/acquired rewards;

BAS - Drive: motivation to achieve desired goals;

BAS - Fun Seeking: willingness to approach new appetitive stimuli

Emotional Stability/

Neuroticism: Capability of controlling one's affect and emotional reactions Extraversion/ Introversion: activity, enthusiasm, and selfconfidence (e.g. 'I like to joke')

Self-Esteem: a person's overall evaluation of his or her worthiness as a human being

Negative urgency: tendency to experience strong reactions under conditions of intense negative affect

Positive urgency: tendency to experience strong reactions under conditions of intense positive affect

Lack of premeditation: tendency to fail to think and reflect on the consequences of an act
5 -point ranging from
0 (Not at all) to 4
(Extremely)

$7 \quad 5$-point ranging from 1 (not describe me at all)

to 5 (describes me completely) for both the BIS and BAS scales

BIS: 0.83

Total score: 0.92

Reassurance seeking

BAS-RR: 0.78

Extraversion

BAS-Drive: 0.70

BAS-Fun: 0.78

Emotional Stability: 0.75

Reassurance (completely true) to 5 (completely false)

Extraversion: 0.75

Extraversion

10 4-point ranging from 1 (strongly disagree) to 4 (strongly agree)

20 4-point ranging from 1 (strongly agree) to 4 (strongly disagree)

0.90

Reassurance seeking

Negative urgency: Impulsive 0.82

Positive urgency: 0.79

Lack of

Premeditation: 0.82 
Table 1. Continued

\begin{tabular}{|c|c|c|c|c|c|c|}
\hline Tools & $\begin{array}{l}\text { Authors (Italian } \\
\text { version) }\end{array}$ & Definition & Items & Likert response format & $\begin{array}{l}\text { Reliability values } \\
\text { (Cronbach's alpha) }\end{array}$ & $\begin{array}{c}\text { Postulated } \\
\text { pathway }\end{array}$ \\
\hline & & $\begin{array}{c}\text { before engaging in that } \\
\text { act }\end{array}$ & & & & \\
\hline & & $\begin{array}{c}\text { Lack of perseverance: } \\
\text { difficulties remaining } \\
\text { focused on a task that } \\
\text { may be long, boring, or } \\
\text { difficult }\end{array}$ & & & $\begin{array}{l}\text { Lack of Perseverance: } \\
0.90\end{array}$ & \\
\hline & & $\begin{array}{l}\text { Sensation-seeking: the } \\
\text { tendency to enjoy and } \\
\text { pursue exciting activities } \\
\text { and an openness to } \\
\text { trying new experiences } \\
\text { that may or may not be } \\
\text { dangerous }\end{array}$ & & & $\begin{array}{l}\text { Sensation Seeking: } \\
0.87\end{array}$ & \\
\hline AQ & $\begin{array}{l}\text { Buss \& Perry, } 1992 \\
\text { (Fossati, Maffei, } \\
\text { Acquarini \& Di Ceglie, } \\
\text { 2003) }\end{array}$ & $\begin{array}{l}\text { Trait aggressiveness } \\
\text { which measures four } \\
\text { components of } \\
\text { aggression: physical } \\
\text { aggression; verbal } \\
\text { aggression; anger; and } \\
\text { hostility. }\end{array}$ & 29 & $\begin{array}{l}\text { 5-point ranging from } 1 \\
\text { (uncharacteristic of } \\
\text { me) to } 5 \text { (very } \\
\text { characteristic of me) }\end{array}$ & 0.89 & Impulsive \\
\hline \multirow[t]{2}{*}{ LSRP } & $\begin{array}{l}\text { Levenson, Kiehl \& } \\
\text { Fitzpatrick, } 1995 \\
\text { (Somma, Fossati, } \\
\text { Patrick, Maffei \& } \\
\text { Borroni, 2014) }\end{array}$ & $\begin{array}{l}\text { Primary psychopathy: } \\
\text { inclination to lie, lack of } \\
\text { remorse, callousness, and } \\
\text { manipulativeness (e.g. 'I } \\
\text { enjoy manipulating other } \\
\text { people's feelings') }\end{array}$ & 26 & $\begin{array}{l}\text { 4-point ranging from } 1 \\
\text { (strongly disagree) to } 4 \\
\quad \text { (strongly agree) }\end{array}$ & $\begin{array}{c}\text { Primary psychopathy: } \\
0.78\end{array}$ & Impulsive \\
\hline & & $\begin{array}{l}\text { Secondary psychopathy: } \\
\text { frustration tolerance, } \\
\text { quick-temperedness, and } \\
\text { lack of long-term goals } \\
\text { (e.g. 'I find myself in the } \\
\text { same kinds of trouble, } \\
\text { time after time') }\end{array}$ & & & $\begin{array}{c}\text { Secondary } \\
\text { psychopathy: } 0.70\end{array}$ & \\
\hline \multirow[t]{3}{*}{$\begin{array}{l}\text { PMPUQ } \\
- \text { SV }\end{array}$} & $\begin{array}{l}\text { Lopez-Fernandez et al., } \\
\qquad(2018)\end{array}$ & $\begin{array}{l}\text { Addictive use: perceived } \\
\text { dependence on the } \\
\text { smartphone (e.g. 'It is } \\
\text { hard for me to turn my } \\
\text { mobile phone off); }\end{array}$ & 15 & $\begin{array}{l}\text { 4-point ranging from } 1 \\
\text { (strongly agree) to } 4 \\
\text { (strongly disagree) }\end{array}$ & Addictive use: 0.81 & \\
\hline & & $\begin{array}{l}\text { Antisocial use: the } \\
\text { tendency to use mobile } \\
\text { phones in contexts where } \\
\text { they are banned (e.g. 'I } \\
\text { don't use my mobile } \\
\text { phone in a library, } \\
\text { cinema or hospital') }\end{array}$ & & & Antisocial use: 0.60 & \\
\hline & & $\begin{array}{l}\text { Dangerous use: } \\
\text { unequivocally risky } \\
\text { behaviours (e.g. 'I use my } \\
\text { mobile phone while } \\
\text { driving') }\end{array}$ & & & Dangerous use:0.84 & \\
\hline
\end{tabular}

List of tools: Depression, Anxiety and Stress Scales - 21 (DASS - 21); Social Interaction Anxiety Scale (SIAS); Carver and White Questionnaire (Behavioural Inhibition System: BIS; Behavioural Activation System: BAS); Italian Version of the Big Five Questionnaire Short Version (BFQ - SV); Rosenberg Self-Esteem Scale (RSES); Short UPPS-P Impulsive Behaviour Scale (S-UPPS-P); Aggression Questionnaire (AQ); Levenson Self-Report Psychopathy Scale (LSRP); Problematic Mobile Phone Use Questionnaire - Short Version (PMPUQ - SV). 
Table 2. (a) Descriptive statistics

\begin{tabular}{|c|c|c|}
\hline & $\mathrm{N}$ of cases/Mean $(\mathrm{SD})$ & Range \\
\hline Sex & Male: 240; Female: 555 & \\
\hline Age & $23.8(3.02)$ & $18-35$ \\
\hline Employment & a:484; b:132; c:43; d:66; e: $70^{1}$ & \\
\hline Relationship & a:264; b:39; c:468; d:6; e:2; f:16² & \\
\hline Living place & 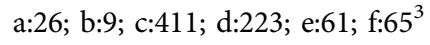 & \\
\hline Addictive mobile phone use & $12.88(3.03)$ & $5-20$ \\
\hline Antisocial mobile phone use & $9.78(2.35)$ & $5-16$ \\
\hline Dangerous mobile phone use & $7.94(2.95)$ & $5-19$ \\
\hline Negative urgency & $9.16(2.60)$ & $4-16$ \\
\hline Positive urgency & $9.24(2.41)$ & $4-16$ \\
\hline Lack of premeditation & $7.56(2.21)$ & $4-16$ \\
\hline Sensation seeking & $9.39(2.83)$ & $4-16$ \\
\hline Self-esteem & $28.50(5.65)$ & $11-40$ \\
\hline Aggression & $70.92(15.95)$ & $36-128$ \\
\hline Neuroticism & $11.94(3.26)$ & $4-20$ \\
\hline Extraversion/introversion & $8.88(2.73)$ & $4-18$ \\
\hline Social anxiety & $28.48(13.10)$ & $1-71$ \\
\hline Stress, depression and anxiety & $20.32(11.06)$ & $0-62$ \\
\hline Primary psychopathy & $30.13(6.15)$ & $19-52$ \\
\hline Secondary psychopathy & $20.97(4.57)$ & $10-38$ \\
\hline BAS-reward responsiveness & $19.55(3.09)$ & $11-25$ \\
\hline BAS-drive & $12.33(2.74)$ & $5-20$ \\
\hline BAS-fun seeking & $11.63(3.07)$ & $4-20$ \\
\hline Behavioural inhibition & $25.17(4.69)$ & $13-35$ \\
\hline
\end{tabular}

${ }_{1} \mathrm{a}=$ Nothing; $\mathrm{b}=$ fixed-term, part-time; $\mathrm{c}=$ permanent, part-time; $\mathrm{d}=$ fixed-term, full-time; $\mathrm{e}=$ permanent, full-time.

${ }^{2} \mathrm{a}=$ Single; $\mathrm{b}=$ casually date; $\mathrm{c}=$ in a committed relationship; $\mathrm{d}=$ married; $\mathrm{e}=$ divorced; $\mathrm{f}=$ widow/widower; $\mathrm{g}=\mathrm{I}$ prefer not to answer.

${ }^{3} \mathrm{a}=$ student residence; $\mathrm{b}=$ college; $\mathrm{c}=$ at your parents' house; $\mathrm{d}=$ house for rent with other students; $\mathrm{e}=$ alone in a house for rent; $\mathrm{f}=$ other. ${ }^{* * *} P<.001 ;{ }^{* *} P<.01 ;{ }^{*} P<.05$. 


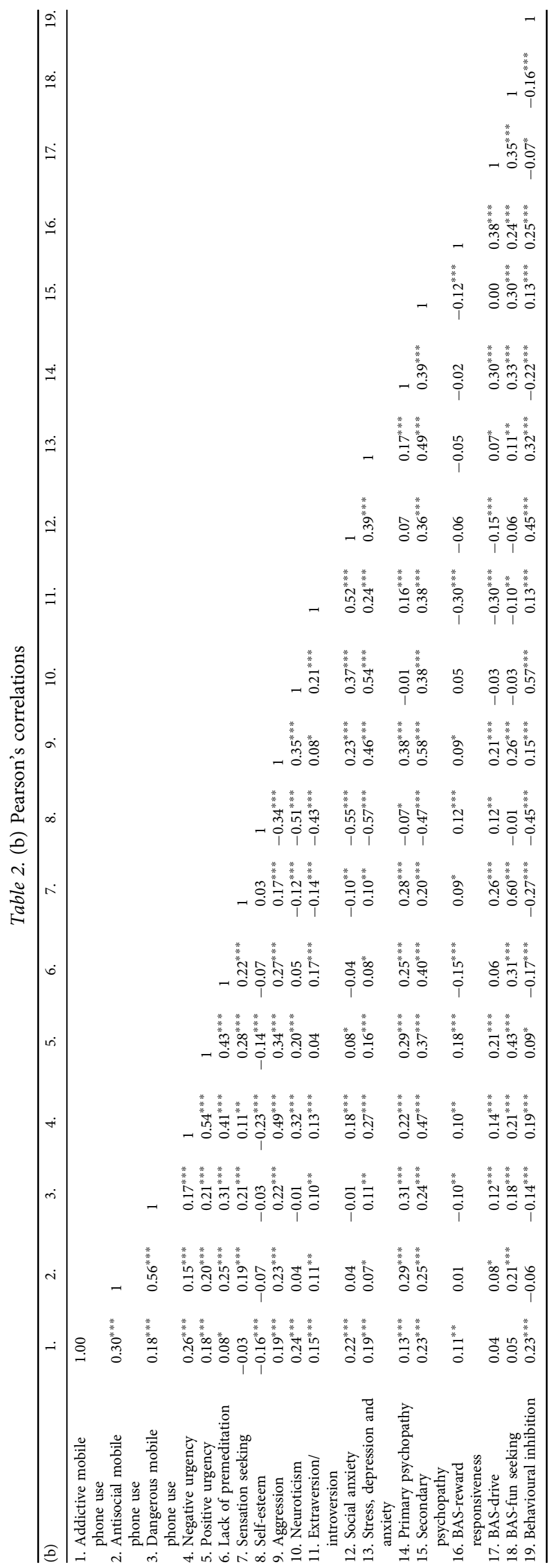

higher sensation seeking $(\beta=0.11,95 \% \mathrm{BCI}=[0.04 ; 0.18])$ and higher primary psychopathy $(\beta=0.11,95 \% \mathrm{BCI}=$ $[0.07 ; 0.14])$. See Table 3 for a summary of these results.

\section{DISCUSSION}

The aim of the current study was to provide a first comprehensive test of the pathway model of PSU (Billieux et al., 2015) by capitalising on a Bayesian analytical approach. This analysis revealed robust and original results regarding the psychological dimensions associated with each of the postulated pathways of PSU. Consistent with the hypotheses formulated in the pathway model of PSU (Billieux et al., 2015), it appeared that some psychological dimensions played a unique role in explaining PSU (e.g. social anxiety is only associated with addictive smartphone use), whereas other psychological dimensions contribute to more than one type of PSU (e.g. sensation seeking predicts both antisocial and dangerous patterns of PSU). The results for each type of PSU are elaborated below in relation to each of the distinct pathways theorised in the model.

First, our results suggest that addictive smartphone use is mainly driven by the excessive reassurance pathway and the impulsive pathway, for which candidate etiopathological factors include heightened negative urgency (i.e. emotionrelated impulsive behaviours), the hyperactive behavioural inhibition system (i.e. a greater sensitivity to punishment) and symptoms of social anxiety. This pattern of results is consistent with the view that addictive smartphone use is mostly fuelled by negative reinforcement and reflects a compensatory mechanism to regulate aversive emotions (Chen et al., 2017; Elhai et al., 2017) or to alleviate social anxiety symptoms by preferring online social interactions over face-to-face interactions (Enez Darcin et al., 2016). Furthermore, our results are consistent with previous research that linked addictive mobile phone use with negative urgency traits (see Billieux, 2012 for a review) and the hyperactive behavioural inhibition system (Kim et al., 2016). In line with previous research (Elhai et al., 2019a,b), the present study revealed that an addictive pattern of smartphone use is more likely to occur in the context of intense distressing emotions. This view is consistent with previous evidence suggesting that intense negative emotional states impair decision making (Bechara, 2004; Dreisbach, 2006) by causing less discretionary use of information (Forgas \& Bower, 1987) or greater distractibility (Dreisbach \& Goschke, 2004) or, alternatively, by interfering in one's ability to control the urge to use a smartphone (Contractor, Weiss, Tull, \& Elhai, 2017). Thus, individuals with higher negative urgency may be motivated by immediately reinforcing experiences that help to reduce or distract from negative affect in the short term (Inzlicht \& Schmeichel, 2012). The current research also revealed a positive association between social anxiety and addictive smartphone use, confirming previous evidence (Darcin, Noyan, Nurmedov, Yilmaz, \& Dilbaz, 2015; Elhai, Tiamiyu, \& Weeks, 2018). 
Table 3. Hypotheses based on the pathway model of Billieux et al. (2015) and results

\begin{tabular}{|c|c|c|c|c|c|c|c|}
\hline Psychological factors & Reassurance & & Impulsive & & & Extraversion & \\
\hline Social anxiety & 0 & & & & & & \\
\hline Neuroticism & O & & & & & & \\
\hline Self-esteem & 0 & & & & & & \\
\hline Psychological distress\# & O & & & & & & \\
\hline Behavioural inhibition & 0 & & & & & & \\
\hline Negative urgency & & ○ & O & O & & & \\
\hline Positive urgency & & O & $\mathrm{O}$ & $\mathrm{O}$ & & & \\
\hline Lack of premeditation & & O & 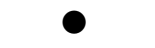 & 0 & & & \\
\hline Aggression & & O & 0 & O & & & \\
\hline Primary psychopathy & & 0 & 0 & 0 & & & \\
\hline Secondary psychopathy & & O & O & O & & & \\
\hline Sensation seeking & & & & & O & 0 & 0 \\
\hline Extraversion & & & & & O & O & O \\
\hline Reward responsiveness & & & & & O & O & O \\
\hline Drive & & & & & O & 0 & O \\
\hline Fun seeking & & & & & 0 & 0 & 0 \\
\hline Type of problematic use & Addictive & Addictive & Antisocial & Dangerous & Addictive & Antisocial & Dangerous \\
\hline
\end{tabular}

$\mathrm{O}=$ hypothesised association; $\mathbf{O}=$ hypothesised and credible association; \#Stress, Depression, and Anxiety.

According to previous studies (Darcin et al., 2015; Enez Darcin et al., 2016), individuals with social anxiety symptoms can be more at risk of displaying addictive smartphone use because social anxiety causes avoidance of face-to-face relationships. For these individuals, virtual socialisation (and communication) via smartphone use can alleviate their fear or concern of showing signs of physiological arousal, and may be guided either by the need to feel free or by the need to behave without the perception of social pressure.

Our results are important in relation to the current debates about the conceptualisation of addictive smartphone use and suggest that this problematic behaviour should preferentially be understood as a maladaptive form of coping rather than a genuine addictive disorder (Harris, Regan, Schueler, \& Fields, 2020; Panova \& Carbonell, 2018). It is worth noting that we cannot exclude the possibility that specific activities performed via the smartphone (such as video gaming or online gambling) constitute discrete addictive behaviours, yet the present study focused on general smartphone use and cannot answer this question. We also found that primary psychopathy - characterised by callousness, shallow affect, manipulation and superficial charm (Levenson, Kiehl, \& Fitzpatrick, 1995; Somma et al., 2014) - is an important predictor of addictive smartphone use. A tenable explanation for this finding is that individuals who are prone to primary psychopathy might perceive themselves as being dependent on the smartphone, as this tool has much functionality that allow one to efficiently manipulate or deceive others.

The present study also revealed that dangerous and antisocial smartphone use are mainly driven by the impulsive pathway and the extraversion pathway, for which candidate etiopathological factors include specific impulsivity components (lack of premeditation and sensation seeking) and primary psychopathy. More specifically, lack of premeditation was reported to have the strongest association with both antisocial and dangerous smartphone use. This specific impulsivity component has been linked to shortterm-based choices and risky decision-making (Zermatten, Van der Linden, d'Acremont, Jermann, \& Bechara, 2005), and it is thus likely that short-term-based choices and a myopia towards long-term consequences favour both antisocial smartphone use (e.g. fines or public disapproval resulting from using the smartphone in a prohibited area) and dangerous use (e.g. lethal risks associated with using the smartphone while driving). In line with the results reported by Billieux et al. (2008), our findings confirm that lack of premeditation is related to prohibited use of the mobile phone and demonstrate (for the first time) its additional association with the dangerous pattern of use. Primary psychopathy also showed positive associations with both dangerous and antisocial smartphone use, while aggressive traits were uniquely linked to an antisocial pattern of smartphone use. These results suggest that individuals with primary psychopathy traits who are aggressive prone possibly use their smartphone as a medium to behave in an antisocial manner (e.g. cyberbullying via social networking sites, Orue \& Calvete, 2019). Lastly, sensation seeking was identified as explaining both the antisocial and the dangerous use of a smartphone. This finding is consistent with previous research showing that heightened sensation seeking is linked to mobile phone-based aggressive behaviours (Kokkinos, Antoniadou, \& Markos, 2014), phoning while driving (Billieux et al., 2008) and sexting (e.g. exchange of sexual pictures via the smartphone) (Dir \& Cyders, 2015), implying that various risky and/or antisocial smartphone-mediated behaviours might be displayed in order to fuel a need for pleasure, excitement or stimulation. We found dangerous and antisocial smartphone use to be specifically related to sensation seeking, as previously found 
by Billieux et al. (2008) and Dey et al. (2019), but not necessarily to the more overarching construct of extraversion (in accordance with Pivetta et al., 2019; Dey et al., 2019). In this regard, Zuckerman and Glicksohn (2016) suggested that the link between sensation seeking and psychoticism is probably more pronounced than that between sensation seeking and extraversion, mainly because both sensation seeking and psychoticism (but not extraversion) are characterised by recklessness and proneness to taking risks (e.g. Jonason, Lyons, Bethell, \& Ross, 2013; Zeigler-Hill \& Vonk, 2015). Thus, we believe that the extraversion pathway should be further investigated and potentially renamed 'the sensation seeking pathway'. Although the antisocial and the dangerous patterns of smartphone use largely overlapped in terms of psychological antecedents, our results showed a key difference between them, namely trait aggression. Aggression is defined as any behaviour directed towards another person aimed at causing harm (Anderson \& Bushman, 2002; Bushman \& Huesmann, 2010), and trait aggression is the individual disposition to behave aggressively. Trait aggression was specifically and solely associated with the antisocial pattern (and not with the dangerous pattern). This difference substantiates the typical behaviours theorised by Billieux et al. (2015) for the two types of PSU. Indeed, our results suggest that the antisocial pattern consists in behaviours not intentionally (and solely) aimed at causing harm to others (e.g. cyberbullying), which can be traced back to trait aggression. Conversely, the dangerous pattern consists of behaviours that, though potentially dangerous for both the smartphone user and other individuals (e.g. phoning while driving might cause a car accident involving the user and other drivers), are not primarily driven by the intention to harm.

Our study has several limitations. Data were collected via self-report measures and were cross-sectional, which precludes any causality statement. Recent studies have used a longitudinal design (Herrero, Torres, Vivas, \& Urueña, 2019; Lapierre, Zhao, \& Custer, 2019; Lee et al., 2020) or a qualitative approach (Yang, Asbury, \& Griffiths, 2019) for the study of smartphone use/dependency or PSU, and further studies that use these alternative methodologies should be conducted to complement our approach. The present study focused on a specific demographic group (i.e., college students with regular access to the Internet, predominantly females), thus limiting the generalisability of our findings. Our results revealed, among the established risk factors for each developmental pathway of PSU, the robust presence of personality traits instead of psychopathological symptoms. Although this result might suggest that stable personality dispositions are better predictors of PSU than potentially transient psychopathological symptoms, we cannot exclude the possibility that it can be explained by the nature of our sample (community sample instead of clinical sample). Future research should focus on more representative, gender-balanced samples of adults and also on clinical (or subclinical) samples. Furthermore, the present study did not consider some psychological factors (e.g. attentional bias and cue reactivity) included in other theoretical frameworks such as the I-PACE model of technology-mediated addictive disorders (Brand et al., 2016, 2019). Finally, the present study did not assess the objective use of smartphones (e.g. daily time spent on social media, tracking data on the number of minutes of screen time and the number of phone screen unlocks; Ellis et al., 2019) or specific smartphone functionalities (e.g. Lowe-Calverley \& Pontes, 2020), and these aspects should be considered and measured in future studies.

Overall, and despite these limitations, our study is the first comprehensive test of the frequently cited pathway model of PSU (Billieux et al., 2015), which was initially formulated to guide research efforts in a research field in which most studies are conducted with an atheoretical and/ or symptom-focused approach. The present study, in addition to providing empirical support to the model, further showed that PSU is a multi-determined and multi-faceted construct, which has to be taken into account when regulating smartphone use or tailoring preventive actions to reduce problematic usage patterns.

Funding sources: This work was partially supported by an intramural grant of the University of Padova (Year: 2018 prot. BIRD183124).

Authors' contribution: NC, TM, GB, AV, MD and JB are responsible for the study concept and design. TM performed analysis. NC and LP supervised the statistical analysis and contribute to the interpretation of data. NC wrote the first draft of the manuscript and all authors critically reviewed and approved the final version of the manuscript.

Conflict of interest: The authors declare no conflict of interest.

\section{SUPPLEMENTARY MATERIAL}

The online version of this article offers supplementary material https://doi.org/10.1556/2006.2020.00103.

\section{REFERENCES}

Anderson, C. A., \& Bushman, B. J. (2002). Human aggression. Annual Review of Psychology, 53, 27-51. https://doi.org/10. 1146/annurev.psych.53.100901.135231.

Augner, C., \& Hacker, G. W. (2012). Associations between problematic mobile phone use and psychological parameters in young adults. International Journal of Public Health, 57(2), 437-441. https://doi.org/10.1007/s00038-011-0234-z.

Bechara, A. (2004). The role of emotion in decision-making: Evidence from neurological patients with orbitofrontal damage. Brain and Cognition, 55, 30e40. https://doi.org/10.1016/j.bandc. 2003.04.001.

Billieux, J. (2012). Problematic use of the mobile phone: A literature review and a pathways model. Current Psychiatry Reviews, 8(4), 299-307. https://doi.org/10.2174/157340012803520522. 
Billieux, J., Maurage, P., Lopez-Fernandez, O., Kuss, D. J., \& Griffiths, M. D. (2015). Can disordered mobile phone use be considered a behavioral addiction? An update on current evidence and a comprehensive model for future research. Current Addiction Reports, 2(2), 156-162. https://doi.org/10.1007/ s40429-015-0054-y.

Billieux, J., Rochat, L., Ceschi, G., Carré, A., Offerlin-Meyer, I., Defeldre, A. C., .. \& \& Van der Linden, M. (2012). Validation of a short French version of the UPPS-P impulsive behavior scale. Comprehensive Psychiatry, 53(5), 609-615. https://doi.org/10. 1016/j.comppsych.2011.09.001.

Billieux, J., Van der Linden, M., \& Rochat, L. (2008). The role of impulsivity in actual and problematic use of the mobile phone. Applied Cognitive Psychology, 22(9), 1195-1210. https://doi.org/ 10.1002/acp.1429.

Billieux, J., Van Rooij, A. J., Heeren, A., Schimmenti, A., Maurage, P., Edman, J., .. \& \& Kardefelt-Winther, D. (2017). Behavioural addiction open definition 2.0-Using the open science framework for collaborative and transparent theoretical development. Addiction, 112(10), 1723-1724. https://doi.org/10.1111/add. 13938.

Bottesi, G., Ghisi, M., Altoè, G., Conforti, E., Melli, G., \& Sica, C. (2015). The Italian version of the Depression Anxiety Stress Scales-21: Factor structure and psychometric properties on community and clinical samples. Comprehensive Psychiatry, 60, 170-181. https://doi.org/10.1016/j.comppsych.2015.04.005.

Brand, M., Wegmann, E., Stark, R., Müller, A., Wölfling, K., Robbins, T. W., et al. (2019). The Interaction of Person-AffectCognition-Execution (I-PACE) model for addictive behaviors: Update, generalization to addictive behaviors beyond internetuse disorders, and specification of the process character of addictive behaviors. Neuroscience \& Biobehavioral Reviews, 104, 1-10. https://doi.org/10.1016/j.neubiorev.2019.06.032.

Brand, M., Young, K. S., Laier, C., Wölfling, K., \& Potenza, M. N. (2016). Integrating psychological and neurobiological considerations regarding the development and maintenance of specific Internet-use disorders: An Interaction of Person-AffectCognition-Execution (I-PACE) model. Neuroscience \& Biobehavioral Reviews, 71, 252-266. https://doi.org/10.1016/j. neubiorev.2016.08.033.

Bushman, B. J., \& Huesmann, L. R. (2010). Aggression. In S. T. Fiske, D. T. Gilbert, \& G. Lindzey (Eds.), Handbook of social psychology (5th ed., pp. 833-863). New York: John Wiley \& Sons.

Buss, A. H., \& Perry, M. (1992). The aggression questionnaire. Journal of Personality and Social Psychology, 63(3), 452. https:// doi.org/10.1037/0022-3514.63.3.452.

Caprara, G. V., Barbaranelli, C., Borgogni, L., \& Perugini, M. (1993). The big five questionnaire: A new questionnaire for the measurement of the five factor model. Personality and Individual Differences, 15, 281-288. https://doi.org/10.1016/01918869(93)90218-R.

Carver, C. S., \& White, T. (1994). Behavioural inhibition, behavioural activation, and affective responses to impendingreward and punishment: The BIS/BAS scales. Journal of Personality and Social Psychology, 67, 319-333.

Cheever, N. A., Rosen, L. D., Carrier, L. M., \& Chavez, A. (2014). Out of sight is not out of mind: The impact of restricting wireless mobile device use on anxiety levels among low, moderate and high users. Computers in Human Behavior, 37, 290-297. https://doi.org/10.1016/j.chb.2014.05.002.

Chen, B., Liu, F., Ding, S., Ying, X., Wang, L., \& Wen, Y. (2017). Gender differences in factors associated with smartphone addiction: A cross-sectional study among medical college students. BMC Psychiatry, 17(1), 1-9. https://doi.org/10.1186/ s12888-017-1503-z.

Choliz, M. (2010). Mobile phone addiction: A point of issue. Addiction, 105(2), 373-374. https://doi.org/10.1111/j.13600443.2009.02854.x.

Clyde, M. A., Ghosh, J., \& Littman, M. L. (2011). Bayesian adaptive sampling for variable selection and model averaging. Journal of Computational and Graphical Statistics, 20(1), 80-101. https:// doi.org/10.1198/jcgs.2010.09049.

Contractor, A. A., Weiss, N. H., Tull, M. T., \& Elhai, J. D. (2017). PTSD's relation with problematic smartphone use: Mediating role of impulsivity. Computers in Human Behavior, 75, 177183. https://doi.org/10.1016/j.chb.2017.05.018.

D'Orta, I., Burnay, J., Aiello, D., Niolu, C., Siracusano, A., Timpanaro, L., . . \& Billieux, J. (2015). Development and validation of a short Italian UPPS-P impulsive behavior scale. Addictive Behaviors Reports, 2, 19-22. https://doi.org/10.1016/j.abrep.2015.04.003.

Darcin, A. E., Noyan, C., Nurmedov, S., Yilmaz, O., \& Dilbaz, N. (2015). Smartphone addiction in relation with social anxiety and loneliness among university students in Turkey. European Psychiatry, 30, 505. https://doi.org/10.1016/S0924-9338(15) 30398-9.

De-Sola Gutiérrez, J., Rodríguez de Fonseca, F., \& Rubio, G. (2016). Cell-phone addiction: A review. Frontiers in Psychiatry, 7, 175. https://doi.org/10.3389/fpsyt.2016.00175.

Dey, M., Studer, J., Schaub, M. P., Gmel, G., Ebert, D. D., Lee, J. Y. C., et al. (2019). Problematic smartphone use in young Swiss men: Its association with problematic substance use and risk factors derived from the pathway model. Journal of Behavioral Addictions, 8(2), 326-334. https://doi.org/10.1556/ 2006.8.2019.17.

Dir, A. L., \& Cyders, M. A. (2015). Risks, risk factors, and outcomes associated with phone and internet sexting among university students in the United States. Archives of Sexual Behavior, 44(6), 1675-1684. https://doi.org/10.1007/s10508-014-0370-7.

Dreisbach, G. (2006). How positive affect modulates cognitive control: The costs and benefits of reduced maintenance capability. Brain and Cognition, 60, 11e19. https://doi.org/10.1016/j. bandc.2005.08.003.

Dreisbach, G., \& Goschke, T. (2004). How positive affect modulates cognitive control: Reduced perseveration at the cost of increased distractibility. Journal of Experimental Psychologylearning Memory and Cognition, 30, 343e352. https://doi.org/ 10.1037/0278-7393.30.2.343.

Ehrenberg, A., Juckes, S., White, K. M., \& Walsh, S. P. (2008). Personality and self-esteem as predictors of young people's technology use. CyberPsychology and Behavior, 11(6), 739-741. https://doi.org/10.1089/cpb.2008.0030.

Elhai, J. D., Dvorak, R. D., Levine, J. C., \& Hall, B. J. (2017). Problematic smartphone use: A conceptual overview and systematic review of relations with anxiety and depression psychopathology. Journal of Affective Disorders, 207, 251-259. https://doi.org/10.1016/j.jad.2016.08.030. 
Elhai, J. D., Levine, J. C., \& Hall, B. J. (2019). The relationship between anxiety symptom severity and problematic smartphone use: A review of the literature and conceptual frameworks. Journal of Anxiety Disorders, 62, 45-52. https://doi.org/ 10.1016/j.janxdis.2018.11.005.

Elhai, J. D., Tiamiyu, M., \& Weeks, J. (2018). Depression and social anxiety in relation to problematic smartphone use. Internet Research, 28(2), 315-332. https://doi.org/10.1108/IntR-012017-0019.

Elhai, J. D., Yang, H., \& Montag, C. (2019). Cognitive-and emotionrelated dysfunctional coping processes: Transdiagnostic mechanisms explaining depression and anxiety's relations with problematic smartphone use. Current Addiction Reports, 6(4), 410-417. https://doi.org/10.1007/s40429-019-00260-4.

Ellis, D. A., Davidson, B. I., Shaw, H., \& Geyer, K. (2019). Do smartphone usage scales predict behavior? International Journal of Human-Computer Studies, 130, 86-92. https://doi.org/10. 1016/j.ijhcs.2019.05.004.

Emirtekin, E., Balta, S., Sural, İ., Kircaburun, K., Griffiths, M.D., \& Billieux, J. (2019). The role of childhood emotional maltreatment and body image dissatisfaction in problematic smartphone use among adolescents. Psychiatry Research, 271, 634639. https://doi.org/10.1016/j.psychres.2018.12.059.

Enez Darcin, A., Kose, S., Noyan, C. O., Nurmedov, S., Yllmaz, O., \& Dilbaz, N. (2016). Smartphone addiction and its relationship with social anxiety and loneliness. Behaviour \& Information Technology, 35(7), 520-525. https://doi.org/10.1080/0144929X. 2016.1158319.

Fjeldsoe, B. S., Marshall, A. L., \& Miller, Y. D. (2009). Behavior change interventions delivered by mobile telephone shortmessage service. American Journal of Preventive Medicine, 36(2), 165-173. https://doi.org/10.1016/j.amepre.2008.09.040.

Forgas, J. P., \& Bower, G. H. (1987). Mood effects on personperception judgments. Journal of Personality and Social Psychology, 53, 53e60.

Fossati, A., Maffei, C., Acquarini, E., \& Di Ceglie, A. (2003). Multigroup confirmatory component and factor analyses of the Italian version of the Aggression Questionnaire. European Journal of Psychological Assessment, 19(1), 54. https://doi.org/ 10.1027//1015-5759.19.1.54.

Fragoso, T. M., Bertoli, W., \& Louzada, F. (2018). Bayesian model averaging: A systematic review and conceptual classification. International Statistical Review, 86(1), 1-28. https://doi.org/10. 1111/insr.12243.

Giovanelli, A., Ozer, E. M., \& Dahl, R. E. (2020). Leveraging technology to improve health in adolescence: A developmental science perspective. Journal of Adolescent Health, 67(2), S7-S13. https://doi.org/10.1016/j.jadohealth.2020.02.020.

Ha, J. H., Chin, B., Park, D. H., Ryu, S. H., \& Yu, J. (2008). Characteristics of excessive cellular phone use in Korean adolescents. CyberPsychology \& Behavior, 11(6), 783-784. https:// doi.org/10.1089/cpb.2008.0096.

Harris, B., Regan, T., Schueler, J., \& Fields, S. A. (2020). Problematic mobile phone and smartphone use scales: A systematic review. Frontiers in Psychology, 11. https://dx.doi.org/10.3389\% 2Ffpsyg.2020.00672.

Henry, J. D., \& Crawford, J. R. (2005). The short-form version of the Depression Anxiety Stress Scales (DASS-21): Construct validity and normative data in a large non-clinical sample. British Journal of Clinical Psychology, 44(2), 227-239. https:// doi.org/10.1348/014466505X29657.

Herrero, J., Torres, A., Vivas, P., \& Urueña, A. (2019). Smartphone addiction and social support: A three-year longitudinal study. Psychosocial Intervention, 28, 111-118. https://doi.org/10.5093/ pi2019a6.

Igarashi, T., Motoyoshi, T., Takai, J., \& Yoshida, T. (2008). No mobile, no life: Self-perception and text-message dependency among Japanese high school students. Computers in Human Behavior, 24(5), 2311-2324. https://doi.org/10.1016/j.chb.2007. 12.001 .

Inzlicht, M., \& Schmeichel, B. J. (2012). What is ego depletion? Toward a mechanistic revision of the resource model of selfcontrol. Perspectives on Psychological Science, 7, 450e463. https://doi.org/10.1177\%2F1745691612454134.

Jonason, P. K., Lyons, M., Bethell, E. J., \& Ross, R. (2013). Different routes to limited empathy in the sexes: Examining the links between the Dark Triad and empathy. Personality and Individual Differences, 54(5), 572-576. https://doi.org/10.1016/j. paid.2012.11.009.

Khang, H., Kim, J. K., \& Kim, Y. (2013). Self-traits and motivations as antecedents of digital media flow and addiction: The Internet, mobile phones, and video games. Computers in $\mathrm{Hu}$ man Behavior, 29(6), 2416-2424. https://doi.org/10.1016/j.chb. 2013.05.027.

Kim, Y., Jeong, J. E., Cho, H., Jung, D. J., Kwak, M., Rho, M. J., . . \& Choi, I. Y. (2016). Personality factors predicting smartphone addiction predisposition: Behavioral inhibition and activation systems, impulsivity, and self-control. PloS One, 11(8). https:// doi.org/10.1371/journal.pone.0159788.

Kokkinos, C. M., Antoniadou, N., \& Markos, A. (2014). Cyberbullying: An investigation of the psychological profile of university student participants. Journal of Applied Developmental Psychology, 35(3), 204-214. https://doi.org/10.1016/j.appdev. 2014.04.001.

Kruschke, J. (2014). Doing bayesian data analysis: A tutorial with $R$, JAGS, and stan. Cambridge: Academic Press.

Lapierre, M. A., Zhao, P., \& Custer, B. E. (2019). Short-term longitudinal relationships between smartphone use/dependency and psychological well-being among late adolescents. Journal of Adolescent Health, 65(5), 607-612. https://doi.org/10.1016/j. jadohealth.2019.06.001.

Lee, S. Y., Lee, H. K., Choi, J. S., Bang, S. Y., Park, M. H., Jung, K. I., et al. (2020). The Matthew effect in recovery from smartphone addiction in a 6-month longitudinal study of children and adolescents. International Journal of Environmental Research and Public Health, 17(13), 4751. https://doi.org/10.3390/ ijerph17134751.

Leone, L., Pierro, A., \& Mannetti, L. (2002). Validità della versione italiana delle scale BIS/BAS di Carver e white (1994): Generalizzabilità della struttura e relazioni con costrutti affini. Giornale Italiano di Psicologia, 29(2), 413-436. https://doi.org/ 10.1421/1245.

Lepp, A., Barkley, J. E., \& Karpinski, A. C. (2014). The relationship between cell phone use, academic performance, anxiety, and satisfaction with life in college students. Computers in Human Behavior, 31, 343-350. https://doi.org/10.1016/j.chb.2013.10.049. 
Lepp, A., Li, J., Barkley, J. E., \& Salehi-Esfahani, S. (2015). Exploring the relationships between college students' cell phone use, personality and leisure. Computers in Human Behavior, 43, 210-219. https://doi.org/10.1016/j.chb.2014.11.006.

Levenson, M. R., Kiehl, K. A., \& Fitzpatrick, C. M. (1995). Assessing psychopathic attributes in a non-institutionalized population. Journal of Personality and Social Psychology, 68,151-158. https://psycnet.apa.org/doi/10.1037/0022-3514.68.1.151.

Lopez-Fernandez, O., Kuss, D. J., Pontes, H. M., Griffiths, M. D., Dawes, C., Justice, L. V., \& Billieux, J. (2018). Measurement invariance of the short version of the problematic mobile phone use questionnaire (PMPUQ-SV) across eight languages. International Journal of Environmental Research and Public Health, 15(6), 1213. https://doi.org/10.3390/ijerph15061213.

Lowe-Calverley, E., \& Pontes, H. M. (2020). Challenging the concept of smartphone addiction: An empirical pilot study of smartphone usage patterns and psychological well-being. Cyberpsychology, Behavior, and Social Networking, 23(8), 550556. https://doi.org/10.1089/cyber.2019.0719.

Lu, X., Katoh, T., Chen, Z., Nagata, T., \& Kitamura, T. (2014). Text messaging: Are dependency and excessive use discretely different for Japanese university students?. Psychiatry Research, 216(2), 255-262. https://doi.org/10.1016/j.psychres.2013.12.024.

Mattick, R. P., \& Clarke, C. J. (1998). Development and validation of measures of socialphobia scrutiny fear and social interaction anxiety. Behaviour Research and Therapy, 36, 455-470. https:// doi.org/10.1016/S0005-7967(97)10031-6.

Montag, C., Wegmann, E., Sariyska, R., Demetrovics, Z., \& Brand, M. (2020). How to overcome taxonomical problems in the study of Internet use disorders and what to do with "smartphone addiction"? Journal of Behavioral Addictions, in press. https://doi.org/10.1556/2006.8.2019.59.

Orue, I., \& Calvete, E. (2019). Psychopathic traits and moral disengagement interact to predict bullying and cyberbullying among adolescents. Journal of Interpersonal Violence, 34(11), 2313-2332. https://doi.org/10.1177\%2F0886260516660302.

Panova, T., \& Carbonell, X. (2018). Is smartphone addiction really an addiction? Journal of Behavioral Addictions, 7(2), 252-259. https://doi.org/10.1556/2006.7.2018.49.

Patton, J. H., Stanford, M. S., \& Barratt, E. S. (1995). Factor structure of the Barratt impulsiveness scale. Journal of Clinical Psychology, 51(6), 768-774. https://doi.org/10.1002/10974679(199511)51:6<768::AID-JCLP2270510607>3.0.CO;2-1.

Pivetta, E., Harkin, L., Billieux, J., Kanjo, E., \& Kuss, D. J. (2019). Problematic smartphone use: An empirically validated model. Computers in Human Behavior, 100, 105-117. https://doi.org/ 10.1016/j.chb.2019.06.013.

Prezza, M., Trombaccia, F.R., \& Armento, L. (1997). La scala dell'autostima di Rosenberg: Traduzione e validazione italiana. Bollettino di Psicologia Applicata, 223, 35-44.

R Core Team (2018). R: A language and environment for statistical computing. R Foundation for Statistical Computing. Retrieved from https://www.R-project.org/.
Rosenberg, M. (1989). Society and the adolescent self-image. (Rev. ed.). Middeltown, CT: Wesleyan University Press.

Schönbrodt, F. D., Wagenmakers, E.-J., Zehetleitner, M., \& Perugini, M. (2017). Sequential hypothesis testing with Bayes factors: Efficiently testing mean differences. Psychological Methods, 22(2), 322. https://psycnet.apa.org/doi/10.1037/ met0000061.

Sica, C., Musoni, I., Chiri, L. R., Bisi, B., Lolli, V., \& Sighinolfi,C.(2007). Social PhobiaScale (SPS) e Social Interaction Anxiety Scale (SIAS): traduzione ed adattamentoitaliano [Social Phobia Scale (SPS) and Social Interaction Anxiety Scale (SIAS): Their psychometric properties on Italian population]. Bollettino di Psicologia Applicata, 252, 59-71.

Smetaniuk, P. (2014). A preliminary investigation into the prevalence and prediction of problematic cell phone use. Journal of Behavioral Addictions, 3(1), 41-53. https://doi.org/10.1556/jba. 3.2014.004.

Somma, A., Fossati, A., Patrick, C., Maffei, C., \& Borroni, S. (2014). The three-factor structure of the Levenson self-report psychopathy scale: Fool's gold or true gold? A study in a sample of Italian adult non-clinical participants. Personality and Mental Health, 8(4), 337-347. https://doi.org/10.1002/ pmh.1267.

Wagenmakers, E. J., Marsman, M., Jamil, T., Ly, A., Verhagen, J., Love, J., et al. (2018). Bayesian inference for psychology. Part I: Theoretical advantages and practical ramifications. Psychonomic Bulletin \& Review, 25(1), 35-57. https://doi.org/10.3758/ s13423-017-1343-3.

Walsh, S. D., Sela, T., De Looze, M., Craig, W., Cosma, A., HarelFisch, Y., .. \& \& Ng, K. (2020). Clusters of contemporary risk and their relationship to mental well-being among 15-year-old adolescents across 37 countries. Journal of Adolescent Health, 66(6), S40-S49. https://doi.org/10.1016/j.jadohealth.2020.02.012.

West, R. (2016). Using Bayesian analysis for hypothesis testing in addiction science. Addiction, 111(1), 3-4. https://doi.org/10. 1111/add.13053.

Yang, Z., Asbury, K., \& Griffiths, M. D. (2019). "A cancer in the minds of youth?": A qualitative study of problematic smartphone use among undergraduate students. International Journal of Mental Health and Addiction, 1-13. https://doi.org/10. 1007/s11469-019-00204-z.

Zeigler-Hill, V., \& Vonk, J. (2015). Dark personality features and emotion dysregulation. Journal of Social and Clinical Psychology, 34(8), 692-704. https://doi.org/10.1521/jscp.2015.34. 8.692 .

Zermatten, A., Van der Linden, M., d'Acremont, M., Jermann, F., \& Bechara, A. (2005). Impulsivity and decision making. The Journal of Nervous and Mental Disease, 193(10), 647-650. https://doi.org/10.1097/01.nmd.0000180777.41295.65.

Zuckerman, M., \& Glicksohn, J. (2016). Hans Eysenck's personality model and the constructs of sensation seeking and impulsivity. Personality and Individual Differences, 103, 48-52. https://doi. org/10.1016/j.paid.2016.04.003.

\footnotetext{
Open Access. This is an open-access article distributed under the terms of the Creative Commons Attribution-NonCommercial 4.0 International License (https:// creativecommons.org/licenses/by-nc/4.0/), which permits unrestricted use, distribution, and reproduction in any medium for non-commercial purposes, provided the original author and source are credited, a link to the CC License is provided, and changes - if any - are indicated.
} 